\section{Decreased Antihyperglycemic Drug Use Driven by High Out-of- Pocket Costs Despite Medicare Coverage Gap Closure}

Diabetes Care 2020;43:2121-2127 | https://doi.org/10.2337/dc19-1880

\section{OBJECTIVE}

Using the 2016 Medicare Part D coverage gap as an example, we explored effects of increased out-of-pocket costs on adherence to branded dipeptidyl peptidase 4 inhibitors (DPP-4i) in patients without financial subsidies relative to subsidized patients who do not experience increased spending during the gap. We also explored seasonality of reinitiation, because discontinuers may be more likely to reinitiate in January when benefits reset.

\section{RESEARCH DESIGN AND METHODS}

We identified DPP-4i or sulfonylurea initiators, aged $\geq 66$ years, from a $20 \%$ sample of 2015-2016 Medicare claims. Difference-in-differences Poisson regression was used to compare adherence before and after entering the coverage gap between nonsubsidized and subsidized patients. Among discontinuers, monthly hazard ratios (HRs) for reinitiation relative to January 2016 were derived with Cox models. As a second control, we repeated analyses using sulfonylureas, generic low-cost alternatives.

\section{RESULTS}

In 2016, 8,096 subsidized and 6,173 nonsubsidized DPP-4i initiators entered the coverage gap. For nonsubsidized patients, copayment in the coverage gap was 45\% (\$227 per DPP-4i prescription), and adherence decreased from $68.4 \%$ to $49.0 \%$ after gap entry. Accounting for adherence differences in subsidized patients, nonsubsidized patients demonstrated reduced adherence to DPP-4i (differencein-difference: $-16.9 \%$; $95 \% \mathrm{Cl}-18.7 \%,-15.1 \%)$ but not sulfonylureas $(-1.6 \%$; $95 \% \mathrm{Cl}-3.4 \%, 0.2 \%)$. Reinitiation was lowest in the months before January (HR 0.4-0.5) among nonsubsidized DPP-4i patients, demonstrating a strong seasonal pattern.

\section{CONCLUSIONS}

Increased out-of-pocket costs negatively affect adherence and reinitiation of branded antihyperglycemic drugs among patients without financial subsidies. Despite closure of the coverage gap, affordability remains a concern given increasing list prices for many drugs on Medicare and the growing use of deductibles and coinsurance by commercial health plans.
Mugdha Gokhale, ${ }^{1,2}$ Stacie B. Dusetzina, ${ }^{3}$ Virginia Pate, ${ }^{2}$ Danielle S. Chun, ${ }^{2}$ John B. Buse, ${ }^{4}$ Til Stürmer, ${ }^{2}$ and Emily W. Gower ${ }^{2}$
${ }^{1}$ Real World Evidence and Epidemiology, GlaxoSmithKline, Collegeville, PA

${ }^{2}$ Department of Epidemiology, Gillings School of Public Health, University of North Carolina, Chapel Hill, NC

${ }^{3}$ Department of Health Policy, Vanderbilt University School of Medicine, Nashville, TN ${ }^{4}$ Department of Medicine, University of North
Carolina School of Medicine, Chapel Hill, NC

Corresponding author: Mugdha Gokhale, mugdha. gokhale@merck.com

Received 20 September 2019 and accepted 2 June 2020

M.G. is currently affiliated with Merck.

This article contains supplementary material online at https://doi.org/10.2337/figshare.12453773.

This article is featured in a podcast available at https://www.diabetesjournals.org/content/ diabetes-core-update-podcasts. 
More than $25 \%$ of older adults (age $\geq 65$ ) in the U.S. have type 2 diabetes. Diabetes is responsible for a large economic burden, with estimated medical costs of nearly $\$ 10,000$ directly attributable to diabetes care per patient annually, much of which is paid by the Medicare program $(1,2)$. Antihyperglycemic treatment is an important component of diabetes management, with better treatment adherence being associated with decreases in $\mathrm{HbA}_{1 \mathrm{c}}$, lower mortality, and lower health care expenditures (3-7).

The supplemental Medicare Part D program, which provides prescription drug coverage to Medicare beneficiaries, has $>43$ million beneficiaries enrolled (8). A unique and long-criticized component of this program was the coverage gap (9), where in 2006 beneficiaries with drug spending over a certain threshold were required to pay full price for their drugs until they reached "catastrophic" spending levels. With the implementation of the Affordable Care Act, beginning in 2011, the amounts that patients were responsible for paying during the coverage gap started to decrease from $100 \%$ of a drug's price in 2010 to $25 \%$ in 2020 $(9,10)$. With the passage of the Bipartisan Budget Act, the coverage gap closed 1 year earlier than planned (cost sharing for branded drugs decreased to $25 \%$ in 2019) (11,12).

The Part $D$ benefit design with the increased out-of-pocket expenditure during the coverage gap is similar in principle to the high-deductible health plans that are currently a predominant commercial health insurance arrangement in the U.S. Like Part D, the high-deductible plans are designed to encourage the use of appropriate medical services and discourage discretionary care in a bid to ensure good health outcomes, while controlling health care spending (13). However, such designs have been shown to delay or discourage crucial care, leading to poor health outcomes. For example, several studies have shown that entering the coverage gap and being exposed to high out-of-pocket costs for medications negatively impact patients' drug use overall and potentially their clinical outcomes (14-17). While the Part D coverage gap closed in 2020, understanding the relationship between high out-of-pocket costs and resource use is still highly relevant given rising drug list prices (on which coinsurance is calculated) and trends in health plans requiring greater cost sharing from patients.

Using the 2016 Medicare Part D coverage gap as an example, we explored the effects of increased out-of-pocket costs on adherence to branded dipeptidyl peptidase 4 inhibitors (DPP-4i) in Medicare beneficiaries without low-income subsidies (approximately two-thirds of Medicare beneficiaries) relative to patients with full subsidies who are not affected by the steep increases in out-of-pocket expenses during the coverage gap. Further, among patients who discontinued and then reinitiated treatment, we explored seasonality in reinitiation because we hypothesized that patients are more likely to reinitiate in January when benefits reset and out-of-pocket costs are lower (18). We used two levels of controls. The first was Medicare beneficiaries with full financial subsidies, where qualifying individuals have a zero/fixed small copayment throughout the year and health care use is unaffected by increased out-of-pocket costs. As a second control, to isolate cost-related adherence changes, we repeated all analyses separately in patients initiating sulfonylureas, the most widely used, low-cost generic antidiabetic drugs (19).

\section{RESEARCH DESIGN AND METHODS}

Study Design, Setting, and Participants This was a retrospective cohort study using a $20 \%$ random sample of the Medicare claims data. The Centers for Medicare and Medicaid Services provides research-identifiable data sets with $5 \%$ and $20 \%$ samples of beneficiaries to groups conducting research. We first identified DPP-4i or sulfonylurea initiators from the random sample of Medicare beneficiaries aged $\geq 66$ years with fee-for-service Part A, B, and D enrollment in at least 1 month during the calendar years 2015 and 2016. We required participants to initiate either a DPP-4i or a sulfonylurea in 2015 after a 6-month washout period without use of the drug of interest. From these groups, we selected patients who filled at least one prescription of the index drug in 2016 and entered the 2016 coverage gap. DPP-4i and sulfonylurea initiators were both stratified into those with no lowincome subsidy (hereafter referred to as nonsubsidized patients) and those with full low-income subsidy benefits (referred to as subsidized patients). Patients with partial low-income subsidy and employer-sponsored coverage were excluded because the Part D data do not include information on the level of monetary support, which makes the medication uptake behaviors systematically different from the nonsubsidized or the fully subsidized beneficiaries.

\section{Primary Variables}

Our primary outcomes of interest were medication adherence and time to reinitiation. Adherence was measured as the proportion of days covered (PDC) before and after entry into the coverage gap using data fields on prescription refills and days' supply. PDC was calculated as the number of days' supply for the study drug class in a certain period (pre- or postcoverage gap period in 2016), divided by the number of days in that period. Being adherent was defined as PDC $\geq 0.80$, a widely used cutoff in the literature (20). Reinitiation was captured as a new fill for a drug in the class of interest after a period of discontinuation ( $\geq 60$ days without the drug after the end of the days' supply of the previous prescription).

\section{Statistical Analyses}

We used a difference-in-difference (DiD) multivariable Poisson regression analysis to measure the effect of entering the coverage gap on medication adherence, evaluating the probability of being adherent to DPP-4i (i.e., PDC $\geq 0.80$ ) (20). The DiD model compared changes in adherence before and after entering the coverage gap for patients whose out-ofpocket costs are likely to increase in the coverage gap (nonsubsidized) versus patients whose out-of-pocket costs remain low and fixed across benefit phases (subsidized). The true coverage gap effect from DiD models is the difference in adherence between the subsidized and nonsubsidized groups in the coverage gap, after subtracting the difference between the subsidized and nonsubsidized groups before entering the coverage gap.

All models were adjusted for demographics, comorbidities, including the Charlson comorbidity index (CCl), and the number of unique drugs prescribed. We defined the $\mathrm{CCl}$ and comorbidities using ICD-9 and ICD-10 diagnosis codes (Supplementary Table 2) and calculated the number of unique drugs based on the number of distinct generic names found in the pharmacy claims. We defined entry 
into the coverage gap and the catastrophic phase as the earliest date on which a beneficiary had any pharmacy claim on which the benefit phase variable indicated entry into or, for the coverage gap, a transition to the next benefit phase. We used pharmacy claims to identify medication costs.

We expect baseline characteristics to differ between subsidized and nonsubsidized patients; thus, a conventional table comparing baseline covariates is not intended to convey covariate balance like in the case of randomized trials or cohort studies (21). However, the critical assumption in DiD analyses is that the differences between groups are stable over time, which is reasonable in this setting because the differences between subsidized and nonsubsidized patients are not expected to vary considerably over 1 calendar year. While it is not necessary to adjust for covariates in DiD analyses (crude and adjusted results tend to be very close), we report both estimates in keeping with recommended best practices (21).

Next, among patients who discontinued index treatment during follow-up (irrespective of whether they entered the coverage gap or not), we assessed the time to reinitiation by monitoring patients from the discontinuation date until reinitiation, death, or the end of the study period (31 December 2016). Using Cox proportional hazard models, we assessed the hazard ratios (HRs) of reinitiation of the index therapy during each calendar month from July 2015 to June 2016, relative to January 2016, separately for beneficiaries with and without subsidies. All models included indicator variables for each calendar month, demographics, comorbidities, and the unique count of prescription medications as covariates. All of the above adherence and reinitiation analyses were repeated separately among sulfonylurea initiators who face limited out-of-pocket costs and serve as a negative control.

We used the Strengthening the Reporting of Observational Studies in Epidemiology (STROBE) reporting recommendations for cohort studies to describe details of the methods and discuss results of this study (22).

\section{RESULTS}

Participants

For DPP-4i, there were 11,594 subsidized

initiators and 12,797 nonsubsidized initiators in 2015. Of these, 8,096 subsidized patients $(69.8 \%)$ and 6,173 nonsubsidized patients (48.2\%) filled at least one prescription of a DPP-4i in 2016 and entered the 2016 coverage gap. For sulfonylureas, 6,183 of 14,093 subsidized initiators (43.9\%) and 5,082 of 20,618 nonsubsidized initiators (24.6\%) filled at least one sulfonylurea prescription in 2016 and entered the 2016 coverage gap.

\section{Descriptive Data}

For both drugs, the subsidized group tended to be predominantly nonwhite and women; in contrast, nonsubsidized patients were predominantly white and approximately half were men (Table 1 ). The subsidized patients were also generally sicker (mean CCl score $\sim 5$ in DPP-4i and sulfonylurea groups) than nonsubsidized patients (mean $\mathrm{CCl}$ score $\sim 4$ in DPP-4i and sulfonylurea groups). Among nonsubsidized DPP-4i initiators, the average out-of-pocket payment per DPP-4i prescription filled during the coverage gap in 2016 was \$227, compared with only \$11 per sulfonylurea prescription filled during the coverage gap. As expected, the differences were minimal for subsidized patients (per-prescription cost of $\$ 3$ for DPP-4i and \$1 for sulfonylurea filled during the coverage gap).

\section{Adherence}

Figure 1 and Table 2 present the DiD analysis results. Among nonsubsidized DPP-4i initiators, more patients were adherent before entering the coverage gap than after, resulting in a difference of -19.4 percentage points. Among subsidized DPP-4i initiators, the corresponding difference was only -2.5 percentage points. After subtracting the difference in adherence among subsidized patients, the effect of facing higher costs reduced adherence of nonsubsidized patients by 16.9\% (adjusted DiD - 16.9\%; 95\% $\mathrm{Cl}-18.7 \%,-15.1 \%)$. In contrast, the difference in the proportion of sulfonylurea initiators being adherent before and after entering the coverage gap was similar in the nonsubsidized and subsidized patients (adjusted DiD -1.6\%; $95 \% \mathrm{Cl}-3.4 \%, 0.2 \%$; adjusted relative risk 0.98; 95\% Cl 0.95, 1.01). Sensitivity analyses in patients restricted to those who entered the coverage gap but not the catastrophic phase in 2016 also yielded similar results (Supplementary Table 1).

\section{Reinitiation}

Among patients initiating DPP-4i in 2015, 10,456 of the nonsubsidized patients $(82 \%)$ and 7,462 of the subsidized patients (64\%) discontinued treatment during follow-up (Supplementary Table 3). The median time to discontinuation was 121 days among nonsubsidized patients and 151 days among subsidized patients. Of those who discontinued, $44 \%$ of the nonsubsidized patients and $51 \%$ of the subsidized patients reinitiated treatment during follow-up. Figure 2 demonstrates the monthly HRs of reinitiation of the discontinued drugs from July 2015 to June 2016, relative to January 2016, for nonsubsidized and subsidized DPP$4 \mathrm{i}$ initiators, separately. Relative to January 2016, for nonsubsidized DPP-4i patients the HR of reinitiation was lower in the months leading up to January when the benefit structure resets, with the lowest HR in December 2015 (HR 0.5; $95 \% \mathrm{Cl} 0.6,0.4)$. In the same population, the HR of reinitiation was also relatively lower in February and gradually decreased over the next few months, but the magnitudes were much lower than the magnitudes observed in the last few months of the calendar year. For the subsidized DPP$4 \mathrm{i}$ patients, the monthly HR of reinitiation varied minimally by month and was at times slightly higher relative to January 2016. Among the sulfonylurea initiators, however, the HRs of reinitiation relative to January 2016 were similar for the nonsubsidized and subsidized groups with overlapping $\mathrm{Cls}$ and no strong temporal pattern. While the HRs for reinitiation in the nonsubsidized group were still lower in the last few calendar months, the magnitudes were much lower than those observed in the case of DPP-4i (Fig. 2).

\section{CONCLUSIONS}

Our results clearly demonstrate that facing increased out-of-pocket costs (in this case due to entry into the coverage gap) negatively affects adherence and reinitiation of branded, relatively expensive antihyperglycemic drugs among patients without financial subsidies. We also observed that patients who discontinued branded antihyperglycemic medications were likely to wait until January to reinitiate discontinued drugs, at a time when the benefit structure resets. Both of these outcomes are particularly relevant for diabetes, because decreased adherence or delaying treatment reinitiation may increase 
Table 1-Characteristics of DPP-4i and sulfonylurea initiators who entered the 2016 coverage gap

\begin{tabular}{|c|c|c|c|c|c|c|}
\hline & $\begin{array}{c}\text { Nonsubsidized } \\
\text { DPP-4i } \\
n=6,173 \\
\end{array}$ & $\begin{array}{c}\text { Subsidized } \\
\text { DPP-4i } \\
n=8,096 \\
\end{array}$ & $\begin{array}{l}\text { SMD } \\
\text { DPP-4i }\end{array}$ & $\begin{array}{c}\text { Nonsubsidized } \\
\text { sulfonylureas } \\
n=5,082 \\
\end{array}$ & $\begin{array}{c}\text { Subsidized } \\
\text { sulfonylureas } \\
n=6,183\end{array}$ & $\begin{array}{c}\text { SMD } \\
\text { sulfonylureas }\end{array}$ \\
\hline Age mean (SD), years & $74.7(6.83)$ & $73.0(9.60)$ & 0.202 & 74.1 (6.92) & $71.4(10.13)$ & 0.31 \\
\hline Sex, male, $n$ (\%) & $3,154(51.1)$ & $2,654(32.8)$ & 0.432 & $2,738(53.9 \%)$ & $2,136(34.5 \%)$ & 0.432 \\
\hline \multicolumn{7}{|l|}{ Race, $n(\%)$} \\
\hline White & $5,515(89.3)$ & $4,421(54.6)$ & 0.472 & $4,583(90.2)$ & $3,501(56.6)$ & 0.449 \\
\hline Black & $317(5.1)$ & $1,790(22.1)$ & 1.087 & $302(5.9)$ & $1,580(25.6)$ & 1.082 \\
\hline Other & $341(5.5)$ & $1,885(23.3)$ & 1.077 & 197 (3.9) & $1,102(17.8)$ & 1.118 \\
\hline Baseline $\mathrm{CCl}$ score, mean (SD) & $4.1(2.70)$ & $4.8(2.76)$ & 0.249 & $4.3(2.69)$ & $5.0(2.80)$ & 0.221 \\
\hline \multicolumn{7}{|l|}{ Comorbidities, $n(\%)$} \\
\hline Retinopathy & $810(13.1)$ & $1,343(16.6)$ & 0.24 & $702(13.8)$ & 984 (15.9) & 0.146 \\
\hline Nephropathy & $778(12.6)$ & $1,169(14.4)$ & 0.141 & $641(12.6)$ & $851(13.8)$ & 0.091 \\
\hline Neuropathy & $1,287(20.8)$ & $2,382(29.4)$ & 0.343 & $1,165(22.9)$ & $1,834(29.7)$ & 0.259 \\
\hline Hyperlipidemia & $5,279(85.5)$ & $6,679(82.5)$ & 0.036 & $4,323(85.1)$ & $4,989(80.7)$ & 0.053 \\
\hline Atherosclerosis & $2,755(44.6)$ & $3,858(47.7)$ & 0.066 & $2,487(48.9)$ & $3,104(50.2)$ & 0.026 \\
\hline Myocardial infarction & $95(1.5)$ & $159(2.0)$ & 0.364 & $94(1.8)$ & $112(1.8)$ & 0.031 \\
\hline Stroke & $464(7.5)$ & $898(11.1)$ & 0.399 & $402(7.9)$ & $717(11.6)$ & 0.391 \\
\hline Chronic kidney disease & $2,008(32.5)$ & $3,070(37.9)$ & 0.155 & $1,781(35.0)$ & $2,361(38.2)$ & 0.087 \\
\hline $\begin{array}{l}\text { Number of drugs prescribed, } \\
\text { mean (SD) }\end{array}$ & $13.2(5.76)$ & $17.6(7.81)$ & 0.636 & $14.4(5.89)$ & $18.3(7.53)$ & 0.584 \\
\hline \multicolumn{7}{|l|}{$\begin{array}{l}\text { Number of prescriptions in the } \\
2016 \text { coverage gap }\end{array}$} \\
\hline DPP-4i prescriptions, mean (SD) & $1.8(2.05)$ & $2.4(2.31)$ & 0.240 & $0.6(1.40)$ & $0.7(1.59)$ & 0.116 \\
\hline $\begin{array}{l}\text { Sulfonylurea prescriptions, } \\
\text { mean (SD) }\end{array}$ & 0.9 (1.59) & $0.8(1.65)$ & 0.037 & $1.7(1.77)$ & $2.1(2.10)$ & 0.205 \\
\hline \multicolumn{7}{|l|}{$\begin{array}{l}\text { Patient pay amount in the } \\
2016 \text { coverage gap }\end{array}$} \\
\hline $\begin{array}{l}\text { Per DPP-4i prescription, } \\
\text { mean (SD), \$ }\end{array}$ & $227.3(144.48)$ & 3.7 (8.39) & 2.186 & 237.0 (151.27) & $3.6(2.53)$ & 2.182 \\
\hline $\begin{array}{l}\text { Per sulfonylurea prescription, } \\
\text { mean (SD), \$ }\end{array}$ & $11.4(15.00)$ & $1.3(1.02)$ & 0.949 & $9.8(15.31)$ & $1.3(1.14)$ & 0.783 \\
\hline \multicolumn{7}{|l|}{ Number of prescriptions (any drug) } \\
\hline In 2016 , mean (SD) & $51.2(36.54)$ & $79.2(67.40)$ & 0.517 & $48.9(39.03)$ & $74.2(68.45)$ & 0.455 \\
\hline $\begin{array}{l}\text { During the } 2016 \text { coverage gap, } \\
\text { mean (SD) }\end{array}$ & $18.8(16.97)$ & 23.7 (20.98) & 0.258 & $15.9(17.37)$ & $22.1(24.07)$ & 0.297 \\
\hline
\end{tabular}

Nonsubsidized patients, patients without low-income subsidy. Subsidized, patients with low-income subsidy. The 2016 coverage gap began once patients reached the plan's initial coverage limit of $\$ 3,310$ and ended when a total of $\$ 4,850$ was spent in 2016 . During the coverage gap, patients were responsible for $45 \%$ of the cost of brand-name drugs. SMD, standardized mean difference.

morbidity, mortality, and additional health care costs (3-7). The above associations were not present for sulfonylureas, which are low-cost generics therapeutically equivalent to DPP-4i (23), highlighting that low out-of-pocket costs do not affect adherence/reinitiation.

Despite the coverage gap being reduced to $25 \%$ coinsurance beginning in 2019 , these results are relevant given the growth in drug list prices over time in Part $D$ and recent increased enrollment in employer-mandated high-deductible commercial health insurance plans. For the latter, such plans require high out-of-pocket payments (annually $\$ 1,000-\$ 7,000$ per patient). Although the timing of the out-ofpocket payment is different from that in the coverage gap, the burden of high cost sharing under such plans is similar in principle to that faced by nonsubsidized beneficiaries under Medicare Part $D$. Recent studies demonstrated that lowincome patients with diabetes in highdeductible plans have increased emergency department visits for diabetes complications and are likely to delay seeking care for macrovascular complications compared with patients in low-deductible plans (13). The subsidized control patients in our study are analogous to the patients in low-deductible plans whose health care use is unlikely to change in response to outof-pocket costs. Recent efforts such as the "Choosing Wisely campaign" (24) have discussed reducing low-value care to avoid unnecessary health care use and reduce costs, but our study, along with the relevant literature, suggests that increasing cost sharing as a means to reduce lowvalue care presents a barrier to appropriate care, particularly in chronic conditions.
In 2016, nonsubsidized patients paid $45 \%$ coinsurance out-of-pocket during the coverage gap. Among the nonsubsidized DPP-4i initiators in our study, this amounted to an average out-of-pocket payment of \$227 for every 30-day DPP-4i prescription filled during the coverage gap. With the coinsurance reduced to $25 \%$ since 2019 with elimination of the coverage gap, nonsubsidized patients will still have to pay $\sim \$ 126$ per DPP-4i prescription ( $\sim 1,500$ annually), a potential affordability problem for many patients. Moreover, the absolute outof-pocket payment increases with an increase in drug prices, imposing a substantial financial burden on patients and resulting in decreased adherence and adverse health outcomes downstream.

The negative association between the coverage gap and adherence in our study 


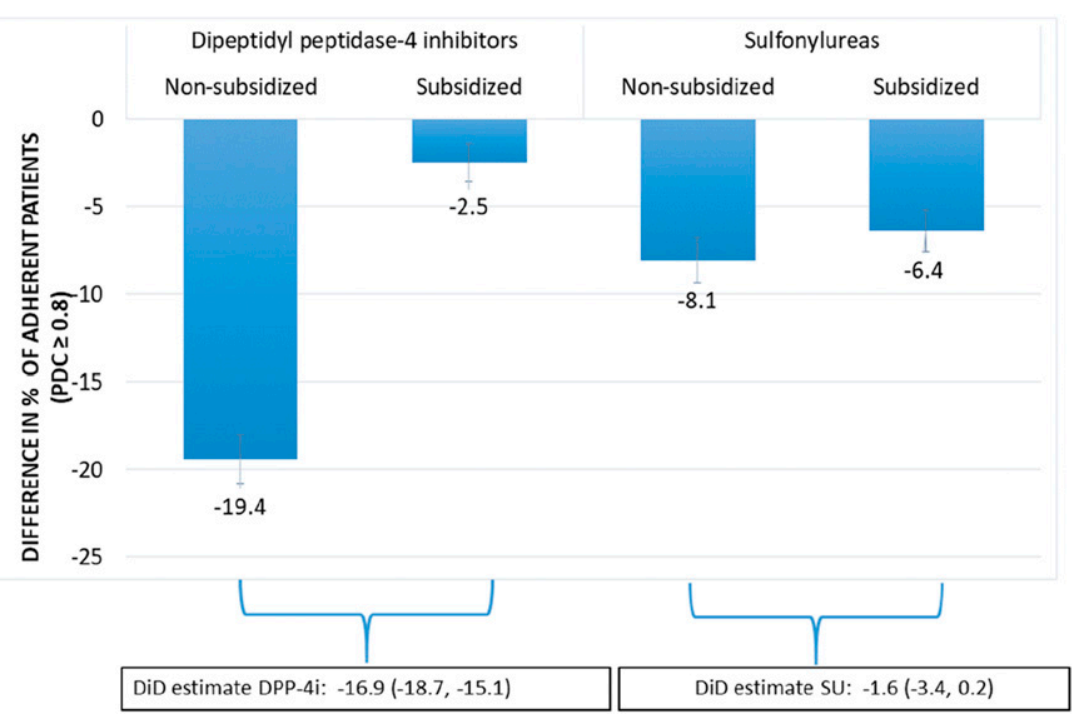

Figure 1-DiD analysis comparing changes in adherence before and after entering the coverage gap in 2016 between subsidized and nonsubsidized patients. SU, sulfonylurea.

is consistent with a previous study that found patients with no or generic-only coverage in the coverage gap were less likely to be adherent to antihyperglycemic treatment after entering the gap in 2008 (14). This previous study assessed adherence to any antihyperglycemic treatment without distinguishing individual drug classes that differ with respect to pricing and brand/generic market penetration and that represent a range of diabetes control, all of which can influence the response to changes in copayment in the coverage gap. A strength of our study is that it explored this question using a more recent year of data (2016), after the Affordable Care Act was passed, and used two levels of controls to isolate the effect of high out-of-pocket costs. One was comparing DPP-4i patients without subsidies to a control group of DPP$4 i$ patients with low-income subsidies that protected the latter group from steep increases in out-of-pocket costs during the coverage gap. The second was separately repeating all analyses in patients initiating sulfonylureas, which are low-cost alternatives to DPP-4i (25). Without directly comparing DPP-4i to sulfonylurea patients in the same analysis, this approach confirmed the hypothesis that due to the low out-of-pocket payment for sulfonylureas during the coverage gap, no substantial changes in adherence before and after the donut hole exist for both patients with and without financial subsidies. Similarly, we did not observe strong temporal patterns for reinitiation among sulfonylurea patients.

Ours is the first study to demonstrate how out-of-pocket payments for patients with diabetes influence the decision to reinitiate discontinued, branded antihyperglycemic medications at the beginning of the calendar year, thereby illustrating forward-looking behavior of patients within a narrow time span. This is in agreement with a previous study that observed reduced monthly medication adherence as the calendar year progressed in response to the donut hole in 2009 (26). It is also interesting to note that while no strong temporal patterns of reinitiation were observed for sulfonylureas, the HRs of reinitiation among nonsubsidized patients were still lower in the last few calendar months of the year. While the magnitudes were much lower for sulfonylureas than those observed in the case of DPP-4i, this implies that being in the coverage gap made patients less likely to fill all medications, although there is a much stronger temporal effect for the more expensive medications.

The results from the current study, based on data from 2016, also provide relevant design and analytic considerations for pharmacoepidemiology studies assessing the comparative safety and effectiveness of antihyperglycemic drugs using real-world Medicare claims data. A major critique of observational exploration of antihyperglycemic drug use in Medicare data is the short time on treatment, which makes it harder to evaluate long-term outcomes. Between $64 \%$ and $82 \%$ of DPP- $4 \mathrm{i}$ initiators in our

Table 2-Results from DiD analyses for the association between the coverage gap and being adherent (PDC $\geq 0.8$ ) for DPP-4i and sulfonylurea initiators who entered the coverage gap in 2016

\begin{tabular}{|c|c|c|c|c|}
\hline & $\begin{array}{l}\% \text { with PDC } \geq 0.8 \\
\text { before coverage gap }\end{array}$ & $\begin{array}{c}\% \text { with } P D C \geq 0.8 \text { while } \\
\text { in coverage gap }\end{array}$ & $\begin{array}{c}\text { Difference (in coverage } \\
\text { gap - before coverage gap) }\end{array}$ & Relative risk $(95 \% \mathrm{Cl})$ \\
\hline \multicolumn{5}{|l|}{ DPP-4i } \\
\hline \multicolumn{5}{|l|}{ Nonsubsidized } \\
\hline patients & $68.4(66.9,69.8)$ & $49.0(47.5,50.5)$ & $-19.4(-20.8,-18.0)$ & \\
\hline Subsidized patients & $73.2(72.1,74.3)$ & $70.7(69.6,71.8)$ & $-2.5(-3.6,-1.4)$ & \\
\hline Coverage effect & & & $-16.9(-18.7,-15.1)$ & $0.76(0.74,0.78)$ \\
\hline \multicolumn{5}{|l|}{ Sulfonylureas } \\
\hline \multicolumn{5}{|l|}{ Nonsubsidized } \\
\hline patients & $68.4(66.8,70.1)$ & $60.4(58.6,62.1)$ & $-8.1(-9.4,-6.8)$ & \\
\hline Subsidized patients & $68.4(67.2,69.7)$ & $62.0(60.7,63.3)$ & $-6.4(-7.7,-5.2)$ & \\
\hline Coverage effect & & & $-1.6(-3.4,0.2)$ & $0.98(0.95,1.01)$ \\
\hline
\end{tabular}

PDC calculated as the number of days' supply for the drug class in a certain period (pre- or postcoverage gap period in 2016), divided by the number of days in that period. All models adjusted for age, sex, race, and comorbidities. Nonsubsidized patients, patients without low-income subsidy. Subsidized patients, patients with full low-income subsidy. 


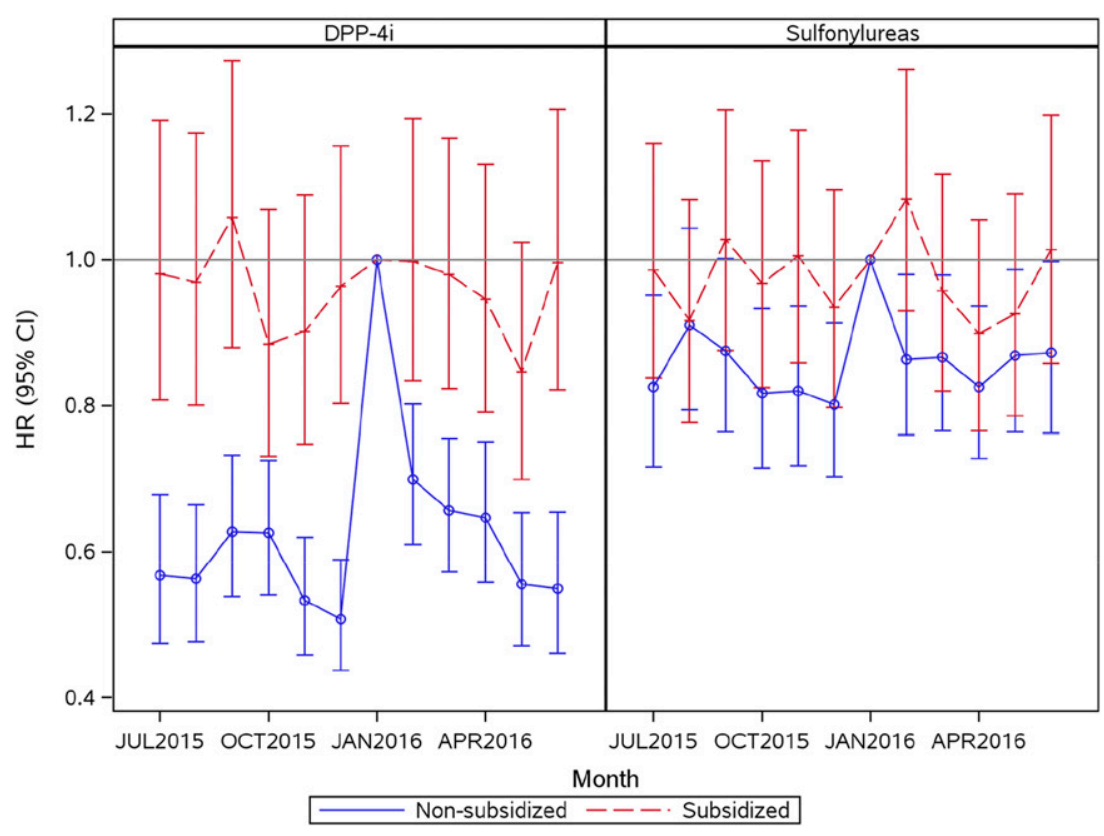

Figure 2-HRs for reinitiation of DPP-4i and sulfonylureas from July 2015 to June 2016 relative to January 2016 among patients who discontinued treatment during follow-up.

study, regardless of financial subsidies, discontinued treatment, with a median time to discontinuation 121-151 days, but approximately half of those who discontinued reinitiated treatment. This implies that cost/benefit structures influence the adherence and reinitiation patterns, which in turn can influence time on treatment, and methods to accurately measure drug exposure (e.g., updating exposure time) in pharmacoepidemiology studies should be considered.

\section{Limitations}

Our study should be interpreted in light of the following caveats. First, insurance claims data do not contain information on whether patients are actually taking the medications as prescribed. Behaviors such as taking medications every other day or cutting doses in half to delay the refill may occur, especially for those using cost-saving strategies. The outcome of adherence in our study defined as PDC using data on prescription refills and days supplied was, therefore, only a proxy for the actual adherence. The degree of inaccuracy in measurement is expected to be uniform in the periods before and after entering the coverage gap, and therefore, this limitation is not expected to significantly affect our conclusions. Second, while we examined the association between the coverage gap and adherence, we could not examine the impact of the coverage gap on clinically important parameters such as $\mathrm{HbA}_{1 \mathrm{c}}$, because these data are not available in Medicare claims. Third, the magnitude of differences observed in this study may not be applicable to other classes of antihyperglycemic drugs or patients with more severe disease. Finally, this study was not designed to assess associations between cost-related nonadherence or delayed reinitiation and long-term health outcomes, but future studies should explore the impact of these on mortality, amputations, and other outcomes of interest.

\section{Conclusion}

Using the example of 2016 Medicare Part D coverage gap, our study demonstrates that increased out-of-pocket costs are associated with poor adherence and delayed reinitiation in patients without financial subsidies for commonly used, branded antihyperglycemic drugs. Despite the Part $D$ gap being reduced to $25 \%$ coinsurance beginning in 2019, these results remain relevant, because prices for branded drugs increase over time and a growing number of patients are exposed to high cost sharing on commercial plans. This is particularly relevant for patients with chronic diseases, such as diabetes, where decreased treatment adherence or health care use may result in downstream negative health outcomes.

Funding. The Medicare database infrastructure used for this work was funded by the Pharmacoepidemiology Gillings Innovation Lab (PEGIL) for the Population-Based Evaluation of Drug Benefits and Harms in Older US Adults (GIL200811.0010); the Center for Pharmacoepidemiology, Department of Epidemiology, University of North Carolina (UNC); UNC's Clinical Translational Science Award from the National Center for Advancing Translational Sciences (UL1TR002489); the Cecil G. Sheps Center for Health Services Research; and the UNC School of Medicine. The development of the state-of-the art nonexperimental methodology was supported by an ongoing grant from the National Institute on Aging (R01AG056479).

Duality of Interest. M.G. is a full-time employee of Merck and reports no conflicts related to the submitted work. S.B.D. is a member of the Institute for Clinical and Economic Review (ICER) Midwest Comparative Effectiveness Public Advisory Council and served on the National Academy of Sciences, Engineering, and Medicine Committee "Ensuring Patient Access to Affordable Drug Therapies"; she receives research support from the Leukemia and Lymphoma Society, The Commonwealth Fund, and Arnold Ventures for unrelated work. D.S.C. is a Bristol-Myers Squibb University of North Carolina Health Economics and Outcomes Research (BMS-UNC-HEOR) predoctoral fellow. J.B.B.'s contracted consulting fees and travel support for contracted activities are paid to UNC by Adocia, AstraZeneca, Dance Biopharm, Eli Lilly, MannKind, NovaTarg, Novo Nordisk, Sanofi, Senseonics, vTv Therapeutics, and Zafgen, as well as grant support from NovaTarg, Novo Nordisk, Sanofi, Tolerion, and vTv Therapeutics. J.B.B. is also a consultant to Cirius Therapeutics Inc., CSL Behring, Mellitus Health, Neurimmune AG, Pendulum Therapeutics, and Stability Health; holds stock/options in Mellitus Health, Pendulum Therapeutics, PhaseBio, and Stability Health; and is supported by grants from the National Institutes of Health (UL1TR002489, P30DK124723), the PatientCentered Outcomes Research Institute, and the American Diabetes Association. T.S. receives salary support from Center for Pharmacoepidemiology (current members: GlaxoSmithKline, UCB BioSciences, Takeda, AbbVie, Boehringer Ingelheim), from Novo Nordisk, and from a generous contribution from Nancy $A$. Dreyer to the Department of Epidemiology, University of North Carolina at Chapel Hill; receives investigator-initiated research funding and support as principal investigator from the National Institute on Aging (R01-AG-056479), as coinvestigator (R01-HL-118255, R01-MD-011680) from the National Institutes of Health; and receives salary support as Director of Comparative Effectiveness Research (CER), North Carolina Translational and Clinical Sciences Institute, UNC Clinical and Translational Science Award (UL1TR002489). T.S. owns stock in Novartis, Roche, BASF, AstraZeneca, and Novo Nordisk. 
No other potential conflicts of interest relevant to this article were reported.

Author Contributions. All authors participated in the conception of the study, design, analysis, writing, and revision of the manuscript. M.G. is the guarantor of this work and, as such, had full access to all the data in the study and takes responsibility for the integrity of the data and the accuracy of the data analysis.

Prior Presentation. Parts of this study were presented in abstract form at the 35th International Conference on Pharmacoepidemiology \& Therapeutic Risk Management, Philadelphia, PA, 24-28 August 2019.

\section{References}

1. Centers for Disease Control and Prevention. National Diabetes Statistics Report. Atlanta, GA, U.S. Department of Health and Human Services, 2020

2. American Diabetes Association. Economic costs of diabetes in the U.S. in 2017. Diabetes Care 2018;41:917-928

3. Asche C, LaFleur J, Conner C. A review of diabetes treatment adherence and the association with clinical and economic outcomes. Clin Ther 2011;33:74-109

4. Donnelly M, Condron C, Murray P, BouchierHayes D. Modulation of the glycemic response using insulin attenuates the pulmonary response in an animal trauma model. J Trauma 2007;63: 351-357

5. Ho PM, Rumsfeld JS, Masoudi FA, et al. Effect of medication nonadherence on hospitalization and mortality among patients with diabetes mellitus. Arch Intern Med 2006;166:1836-1841 6. Rozenfeld Y, Hunt JS, Plauschinat C, Wong KS. Oral antidiabetic medication adherence and glycemic control in managed care. Am J Manag Care 2008:14:71-75

7. Curkendall SM, Thomas N, Bell KF, Juneau PL, Weiss AJ. Predictors of medication adherence in patients with type 2 diabetes mellitus. Curr Med Res Opin 2013;29:1275-1286

8. Henry J Kaiser Family Foundation. An overview of the Medicare Part $D$ prescription drug benefit [Internet], 2019. Available from: https:// www.kff.org/medicare/fact-sheet/an-overviewof-the-medicare-part-d-prescription-drug-benefit/. Accessed 20 September 2019

9. Kirchhoff SM. Medicare Part D Prescription Drug Benefit. Washington, DC, Congressional Research Services, 2018

10. Hoadley J, Cubanski J, Neuman T. Medicare Part D at Ten Years: The 2015 Marketplace and Key Trends, 2006-2015. San Francisco, CA, Henry J Kaiser Family Foundation, 2015

11. Donohue JM, Huskamp HA. Doughnuts and discounts - changes to Medicare Part D under the Bipartisan Budget Act of 2018. N Engl J Med 2018;378:1957-1960

12. Cubanski J, Neuman T, Damico A. Closing the Medicare Part D Coverage Gap: Trends, Recent Changes, and What's Ahead. San Francisco, CA, Henry J Kaiser Family Foundation, 2018

13. Wharam JF, Zhang F, Eggleston EM, Lu CY, Soumerai SB, Ross-Degnan D. Effect of highdeductible insurance on high-acuity outcomes in diabetes: a Natural Experiment for Translation in Diabetes (NEXT-D) study. Diabetes Care 2018; 41:940-948

14. Gu Q, Zeng F, Patel BV, Tripoli LC. Part D coverage gap and adherence to diabetes medications. Am J Manag Care 2010;16:911-918

15. Zhang Y, Donohue JM, Newhouse JP, Lave JR. The effects of the coverage gap on drug spending: a closer look at Medicare Part D. Health Aff (Millwood) 2009;28:w317-w325

16. Park YJ, Martin EG. Medicare Part D's effects on drug utilization and out-of-pocket costs: a systematic review. Health Serv Res 2017;52:1685-1728

17. Joyce GF, Zissimopoulos J, Goldman DP. Digesting the doughnut hole. J Health Econ 2013; 32:1345-1355

18. Kaplan C, Zhang Y. The January effect: medication reinitiation among Medicare Part
D beneficiaries. Health Econ 2014;23:12871300

19. Gokhale M, Buse JB, DeFilippo Mack C, et al. Calendar time as an instrumental variable in assessing the risk of heart failure with antihyperglycemic drugs. Pharmacoepidemiol Drug Saf 2018;27:857-866

20. Karve $S$, Cleves MA, Helm M, Hudson TJ, West DS, Martin BC. Good and poor adherence: optimal cut-point for adherence measures using administrative claims data. Curr Med Res Opin 2009;25:2303-2310

21. Wing C, Simon K, Bello-Gomez RA. Designing difference in difference studies: best practices for public health policy research. Annu Rev Public Health 2018;39:453-469

22. von Elm E, Altman DG, Egger M, Pocock SJ, Gøtzsche PC, Vandenbroucke JP; STROBE Initiative. The Strengthening the Reporting of Observational Studies in Epidemiology (STROBE) statement: guidelines for reporting observational studies. Ann Intern Med 2007;147:573-577

23. Inzucchi SE, Bergenstal RM, Buse JB, et al. Management of hyperglycemia in type 2 diabetes, 2015: a patient-centered approach: update to a position statement of the American Diabetes Association and the European Association for the Study of Diabetes. Diabetes Care 2015;38: 140-149

24. Ferguson T. Improving health outcomes and promoting stewardship of resources: ABIM Foundation's Choosing Wisely campaign. Virtual Mentor 2012;14:880-884

25. Montvida O, Shaw J, Atherton JJ, Stringer F, Paul SK. Long-term trends in antidiabetes drug usage in the U.S.: real-world evidence in patients newly diagnosed with type 2 diabetes. Diabetes Care 2018;41:69-78

26. Sacks NC, Burgess JF Jr., Cabral HJ, Pizer SD. Myopic and forward looking behavior in branded oral anti-diabetic medication consumption: an example from Medicare Part D. Health Econ 2017;26:753-764 